\title{
Competitiveness and Workforce performance: Asia vis-à-vis the "West"
}

\section{Abstract}

Purpose - This eight country study examines what drives performance at the individual worker's level and compares the explanatory power of such drivers between emerging, newly developed and developed markets around the globe.

Design/methodology/approach - The study combines established behavioural theory developed in a Western context with three factors anticipated to be most relevant in Asia (competitive attitude, willingness to serve and speed) as drivers of workforce performance. Four thousand working and middle class respondents from eight countries were sampled. The associations were tested using structural equation modelling and workforce performance was measured using univariate analysis.

Findings - Three country clusters emerged from the research 1) emerging economies in Asia (Indonesia, India) where the three factors powerfully explain performance; 2) 'Confucian orbit countries' (China, Japan, Korea) where the factors explain 81-93\%; and 3) highly developed Western countries (USA, UK, Germany) where the factors account for only 20-29\%.

Practical implications - As well as providing a framework for modelling workforce performance, particularly in Asian countries, the findings indicate that workforce performance should be incorporated in performance indexes. The findings as to which drivers best explain workforce performance in each county can inform workforce recruitment and management, as well as the location of businesses and outsourcing. Originality/value - For the first time, the study addresses the anomaly between the economic growth and development experienced by Asian countries and their relatively low rankings in global competitiveness indexes by making the link between workforce performance and country performance. 
Keywords: Confucian orbit; competitiveness; performance; productivity; workforce performance

Paper type: Research paper 


\section{Introduction}

Asian countries such as China, India and South Korea (hereafter Korea) have experienced economic growth and development over the past few decades beyond that of Western economies with their saturated markets. East Asia also academically outperforms the West in many ways with their highly competitive approach to education (Baumann and Winzar, 2014). And yet global rankings of economic indicators rank them behind Western economies. How can this anomaly be explained?

It could be that Asian workers’ performance at the micro level exceeds that of the West, and that this difference is not yet captured in formal macro level rankings by the World Bank or the World Economic Forum in Davos, Switzerland. This study is designed to explore workers' performance at that micro level, contrasting Asia to the "West”.

Economic indicators such as competitiveness, performance and productivity are generally measured at the macro level by international organisations (World Bank, United Nations, World Economic Forum). Whilst, the literature indicates that the macro and the micro levels of performance are related to one another (Boltho, 1996; Hickman, 1992; Oral et al., 1999) it is possible that the macro level measures of competitiveness, performance and productivity do not fully reflect the individual workers' performance. Thus, the focus of this study is employee performance, which has received much less attention in previous research, particularly cross culturally.

This study focuses on the working and middle-class since from a customer's perspective, front line employees and their direct supervising staff, especially in hospitality and tourism related services, represent the brand. Employee behaviour, friendliness, grooming, deportment, appearance and uniform and of course the actual performance of the service itself are key factors in the formation of customer satisfaction and loyalty. "Front line employees do 
more than just deal with unstructured issues; they exercise their creativity in novel ways to help and advise customers” (Lai et al., 2014, p.1355). In simple terms, happy and peakperforming employees can be viewed as a prerequisite for the ‘service profit chain’ (SPC); in short: good services lead to firm profitability) to work (Heskett and Schlesinger, 1994). It is therefore crucial to understand the drivers of front line employee performance. For example, Fairhurst's study of “Driving a performance culture through to the front line” at McDonalds (2008, p.321) resulted in a rewards framework that enhanced front line workforce commitment and performance.

This study examines the drivers of front line employee performance, particularly the role of motivation. The conceptual starting point is McClelland's three human needs: achievement, power and affiliation. These needs have been linked to performance in various forms in many studies (Covington, 2000; Frischer, 1993; McNeese-Smith, 1999; Ramlall, 2004). In addition, research has shown that motivations (or human needs) tend to vary across different cultural groups in the ways they are manifested or satisfied (Frischer, 1993; Smith, 2008; Yu and Yang, 1994). This study builds upon McClelland's ideas by incorporating: competitive attitude, willingness to serve, and speed - being speed of life, or speed of 'doing things' (Brislin and Kim, 2003; Garhammer, 2002; Nowell, 2010), in addition to achievement and power as indictors of employee performance (self-perceived). Affiliation was found not to statistically contribute to employee performance, so it was subsequently excluded from this study. McClelland's Human Motivation Theory was chosen for this study as the need for achievement and need for power as both are considered as higher order needs that act as motivator conditions directly related to competitiveness. In contrast, neither Maslow's Hierarchy of Needs nor Hofstede’s Cultural Dimensions Theory include both of these needs and were thus not as well suited as a foundation for this research as McClelland's work. 
As mentioned previously, global rankings of competitiveness, performance and productivity at the macro level generally indicate that Western countries are more competitive and productive than Asian countries. For example, the World Economic Forum's (WEF) Global Competiveness Index (GCI) of 2011-2012 ranks Switzerland, Singapore (an Asian country, yet one with a strong British heritage) and Sweden as the most competitive, whereas Asian countries such as Korea and China rank $24^{\text {th }}$ and $26^{\text {th }}$ respectively (Schwab and Sala-i-Martin, 2011). These global indexes were designed in a Western context. However, with China and India becoming major global economies and the East Asian countries such as Japan, Korea and Taiwan being at the forefront of technological innovation (consumer electronics, cars) and brand building (service and hospitality brands such as Lotte, Hanwha, Okura and $85^{\circ} \mathrm{C}$ ), it is important to study competitiveness, performance and productivity from an 'Asian perspective' as per Lee et al. (2005) in their review of economic value drivers.

The paper compares employee performance and its explanatory factors in five Asian countries and compares that to three Western countries. In the Asian region, the three largest emerging national markets: China, India, and Indonesia (which has the world’s fourth-largest population and recent economic growth above $6 \%$ per annum), and the more highly but also relatively newly developed Asian markets: Japan and Korea were sampled (UNIDO, 2013). The Western countries sampled are three of the major Western economies; USA, the UK and Germany. The USA has the largest economy in the Americas and the UK and Germany are the largest economies in Europe. All three countries have highly developed markets with strong export industries and strong and high standard hospitality sectors. International tourism data from the World Bank shows 31.545 million people visited Germany; 31.169 million visited the UK; and 69.768 million visited the US in 2013. 
Overall, this study has two key objectives. Firstly, it seeks to examine what drives performance at the individual worker's level, and to compare the explanatory power of such drivers between Asian emerging and newly developed markets and Western developed markets. Secondly, it compares performance levels between these markets.

\section{Theoretical framework}

McClelland's Motivation Theory (1967) is an enduring and influential theory of human motivation. McClelland suggests that people are motivated to act by three 'acquired' needs: the need for achievement, the need for power and the need for affiliation. Despite being acquired, McClelland argues that all three needs exist within all people, regardless of age or culture, and that the dominant need in each person determines the direction taken in life and their subsequent performance.

Although McClelland's work has been influential in understanding employee performance in organisations and with researchers over the decades (see Dickinson, 1995), most of the research is based on people in Western countries whose social and cultural norms differ significantly from the norms in Asian countries. From the perspective of the current study, it is argued that McClelland's theory of motivation cannot fully explain performance in the Asian context because the factors that form the Asian outlook are not fully taken into account. Indeed, Cultural Difference Theory (Banks, 1993; Cole and Bruner, 1971) argues that all cultures differ from one another and have varying assets, or “cultural capital” (Bourdieu, 1997).

Several studies have pointed to factors that are more prevalent in Asia than in Western countries, such as having a competitive attitude (Hwang and Arbaugh, 2006; King et al.; Singh et al., 2008), having a willingness to serve (Ling et al., 1999; Sarros et al., 1997; Smith et al., 2006), and speed of life, or speed of ‘doing things’ (Brislin and Kim, 2003; 
Garhammer, 2002; Nowell, 2010), simply called 'speed' in this study. It is hypothesised that, particularly in Asia, three factors mediate the relationships between the need for achievement and the need for power as well as employee performance.

Competitive attitude, willingness to serve, and speed

East Asian values are heavily influenced by Confucianism. "Confucian Heritage Cultures” (Lee, 1996) place a strong emphasis on family and community, but also on education and performance, hierarchy, and, as a result, a willingness to serve. It has also been argued that East Asian individuals - or specifically the Chinese, Japanese and Koreans - are highly competitive (Chen, 2004).

\section{Competitive Attitude}

Economists typically refer to competitiveness at the macro level (Huggins and Thompson, 2011; Porter, 1980) and the World Economic Forum’s competitiveness ranking, the Global Competitive Index is based on what it defines as the 'twelve pillars of competitiveness' (basic requirements, efficiency enhancers and innovation and sophistication factors). However, the results of such rankings with Western countries ranked highest according to World Economic Forum do not accord with the fact that, in recent years, East Asian economies have outperformed North American and European economies with significantly higher levels of productivity (Chang and Luh, 1999; Wagner, 2007). Thus, this study does not examine competitiveness at the macro level, but the presence of a competitive attitude in the individual.

To measure competitive attitude at the individual level, the study uses a psychometrically sound instrument developed by Ryckman and his colleagues (Ryckman et al., 1996). Variation in competitive attitude in individuals has been well established in the literature 
(Burckle et al., 1999), and there is a strong case, based on the "Ryckman School”, to include competitive attitude at the individual level in the study.

\section{Willingness to Serve}

Willingness to serve has been investigated in prior research, but with a different focus from this study. For example, research has focused on 'willingness to serve' in the context of 'the greater good', such as in the medical field (Martin, 2000; McNeese-Smith, 1999; Serneels et al., 2007; Tu and Ginsburg, 2006). Willingness to serve has also been researched in the context of a 'call to duty', such as in politics/government (Fukurai and Krooth, 2010; Rose et al., 2012; Vigoda, 2000), in human resource management (Ashamalla, 1998) and in societal cultural values (Harris and Shimizu, 2004), ultimately suggesting that willingness to serve in individuals may relate to culture. It has been argued that Confucian culture develops willingness to serve in that it commends serving superiors and customers because of the power distance, manners and respect for elders and others is emphasised in education where teachers pass on manners and discipline.

\section{Speed}

"Speed" in its various forms has been shown to be an important factor in a firm’s performance. These forms include employees’ speed or “pace” of work (Procter and Rowlinson, 2012; Shadur et al., 1995), the speed of a company's response to a competitor's product release (Lynn et al., 1999b), or even the "speed of life” (Nowell, 2010) within a given culture and its impact on businesses based in that culture. "Speed-to-market" (Lynn et al., 1999a), or the time that elapses for a new product to "hit” the market, has been associated with competitiveness since the 1990s, with Vesey (1991) defining it as one of the critical factors in market success. 
This study measures 'speed' as an attitude workers have to themselves and their work. Although measuring the 'speed of life' in one culture over another can be difficult, Levine and colleagues developed and have been working with the framework used in this study since the mid-1980s (Levine and Bartlett, 1984). Levine and Norenzayan (1999) conducted a much larger study, encompassing many countries including Korea and China, and found a significant correlation between speed of life and higher GDP per capita as well as stronger purchasing power.

In sum, the study anticipates that the three characteristics: competitive attitude, willingness to serve, and speed, which are prevalent among Asian cultures, mediate the relationship between a) an individual's need for power and performance, and, b) an individual's need for achievement and performance. Thus, the following hypotheses are proposed:

- $\mathrm{H}_{1 \mathrm{a}}$ : Competitive attitude significantly mediates the relationship between need for achievement and performance.

- $\mathrm{H}_{1 \mathrm{~b}}$ : Willingness to serve significantly mediates the relationship between need for achievement and performance.

- $\mathrm{H}_{1 \mathrm{c}}$ : Speed significantly mediates the relationship between need for achievement and performance.

- $\mathrm{H}_{2 \mathrm{a}}$ : Competitive attitude significantly mediates the relationship between need for power and performance.

- $\mathrm{H}_{2 \mathrm{~b}}$ : Willingness to serve significantly mediates the relationship between need for power and performance.

- $\mathrm{H}_{2 \mathrm{c}}$ : Speed significantly mediates the relationship between need for power and performance. 


\section{Workforce Performance}

Drawing on the work of Woods et al. (1981) on measuring performance/productivity in individuals, this study uses a self-reported measure of performance/productivity, or more simply performance. More specifically, the measure captures how hard the respondents think they are working, how much work they are doing, and how productive they are. Whilst this is not a direct, concrete measure of performance, importantly, the spread in the variable suggests that respondents have been honest in their self-reporting as the results do not all cluster around the top scores.

As already alluded to, the study anticipates higher workforce performance in Asia based on the strong work ethic prominent in countries such as Korea and Japan, as established in a recent study of drivers of work ethic in a cross cultural context (Baumann et al., 2016). Baumann and his colleagues demonstrate that work ethic is formed by performance orientation, impact on workforce and respect passed on in the education system, in both Asian and Western countries. However, strict discipline and a focus on academic performance only drive work ethic in Asia. Thus, there is strong evidence to suggest that work force performance is explained by the pedagogical approach in schools and universities. Cultural factors such as Confucianism in parts of Asia drive a competitive education system, and that in turn drives a competitive economy with a competitive workforce. A similar effect is anticipated in this study, namely it is hypothesised that:

- $\mathrm{H}_{3}$ : Performance is higher in Asian emerging and newly developed markets vis-à-vis Western developed markets. 


\section{Methodology}

This study uses a two-step approach to achieve its research objectives. Firstly, it develops a model in order to explain performance. Secondly, based on this model, it tests the hypothesised associations across the eight countries under investigation.

The model (Figure 1) summarises the hypothesised associations which were tested by applying Structural Equation Modelling (SEM). SEM is widely used in business research, and was chosen for this study for two main reasons. Firstly, SEM allows for a simultaneous testing of direct and indirect, or mediating, effects of latent predictor variables on the latent dependent variable. Secondly, it allows specific testing of the contribution of the explanatory power (R-squared $\left[\mathrm{R}^{2}\right]$ ) to explain the endogenous variables (competitive attitude, willingness to serve, and speed) and the ultimate dependent variable, performance.

\section{Figure 1 near here}

The resultant SEM model was subsequently aligned with the results of a univariate analysis of variance (UNINOVA). The combined results of the SEM and UNINOVA were used to identify clusters of countries.

\section{Method of Data Collection}

This study was conducted in eight countries: Korea, China, Germany, Indonesia, India, Japan, USA and the UK. In order to capture a more representative data set beyond major cities, respondents were sampled in 10 different locations each in China and India, in 14 locations in Indonesia, and in 5 regions each in Germany, Korea, Japan, the USA and the UK. In all, approximately 4,000 samples were collected, 500 from each country.

The questionnaire for this study was designed to measure the respondents' level of performance, competitive attitude, willingness to serve and speed, and also their needs in 
relation to achievement and power on a 7-point Likert scale (Appendix 1 shows the key items used in the study). Respondents also self-declared whether they belong to the working or middle class. The study focussed on these two classes and excluded the "elite" class since the working and middle classes represent the majority within populations and the living conditions for these two classes vary among countries more than the conditions of the elite.

After pre-testing the questionnaire with ten "test-respondents", the questionnaire was translated into Korean, simplified Chinese, Hindi, Bahasa Indonesia, Japanese and German. Translations were conducted by professional translators and each of the six language versions was pre-tested by academics with relevant language backgrounds before data collection. To ensure access to the population of respondents that met the objectives of this study, the questionnaire was administered with the assistance of a professional survey organization.

As mentioned, SEM allowed a comparison of performance and its prediction between the eight countries. The model fit indices of the most parsimonious model developed in this study are all acceptable values. In reviewing the goodness-of-fit statistics, the various fit indices for the model overall include chi-squares that are considered high, with $p$-values close to zero. Although the $p$-values are generally lower than 0.001, suggesting that the chi-square estimations are not low per se, the $p$-values can be considered acceptable given the large sample size of this study. The value of ratio chi-square $\chi^{2}$ to degree of freedom falls into the acceptable range of less than 5.0 (Bollen, 1989), and even less than 3.0, which is preferred (Byrne, 2006). These results are in line with other important fit indices such as a Goodnessof-Fit statistic (GFI), a Normed Fit Index (NFI), and a Confirmatory Fit Index (CFI) that are all around 0.95, and a Root Mean Square Error of Approximation (RMSEA) that is less than 0.05 . 


\section{Common Method Variance}

The self-report method used in this study may create an issue of Common Method Variance (CMV) being "spurious correlation between variables that is created by using the same method - often a survey - to measure each variable” (Craighead et al., 2011, p.578). Chang et al. (2010, p.178) explain that "false correlations [exist] if the respondents have a propensity to provide consistent answers to survey questions that are otherwise not related”. To check for the possibility of CMV in the study, Harman's single factor and unmeasured latent methods construct (Podsakoff et al., 2003) test were conducted to assess the construct validity.

\section{Harman's single factor test}

The Harman's single factor test loads all the measures from each of the constructs into a single confirmatory factor analysis. The presence of CMV can be indicated by the emergence of a single method factor accounting for a majority of the covariance between the measures. Testing the data revealed the following goodness-of-fit indices: $\mathrm{IFI}=0.776$, TLI $=0.737$ and $\mathrm{CFI}=0.775$, indicating a poor fit for the single factor test. This results shows that there is no strong evidence to indicate a single factor accounted for the majority of the covariance in all constructs. While this outcome is positive, the Harman's single factor test should only be treated as a preliminary diagnostic because it is an insensitive test.

\section{Unmeasured latent method construct (ULMC) test}

The ULMC technique modelled all theoretical constructs as indicators into a first order factor, as well as into a latent common methods variance factor. Podsakoff et al. (2003) recommend that ULMC is most appropriately used when the predictor and criterion variables are obtained from the same rater in the same measurement context using the same item context, as in this study. The significance of the structural parameters of the first order factor model was examined both with and without the latent common factor in the model. Table 1 shows the results of the ULMC test for the Korean respondents as an example. 


\section{Table 1 goes about here}

As shown in Table 1, the fit index difference was not significantly different (Chi-Square = 2.370; $p=1.00$ ) while the factor loadings of these items continued to be significant. Thus it is concluded that the common method effects are only minor.

\section{Results}

Table 2 shows the performance $\mathrm{R}^{2}$, the contribution of each independent variable (competitive attitude, willingness to serve and speed) to the performance $\mathrm{R}^{2}$ and the independent sample ttests for the middle class and working class. The contribution to $\mathrm{R}^{2}$ reflects the strength for each construct with its relative contribution to the overall $\mathrm{R}^{2}$. Contribution to $\mathrm{R}^{2}$ is calculated as the proportion of path coefficient multiplied by the coefficient correlation and path coefficient $(\beta * r / \beta)$. The $\mathrm{R}^{2}$ analysis and independent sample t-tests reveal three distinct clusters in explaining performance among the eight countries under investigation, namely Asian countries with emerging markets (Indonesia and India), Asian countries in the Confucian orbit (China, Japan and Korea), and Western countries with highly developed markets (USA, UK and Germany).

\section{Table 2 goes about here}

\section{Asian countries with emerging markets}

Indonesia and India have similar characteristics in statistical terms such as the $\mathrm{R}^{2}$, contribution of independent variables to the $\mathrm{R}^{2}$ of performance and the similar means of performance between the middle and working class. Explanatory power beyond $90 \%$ ( $\mathrm{R}^{2}$ of 0.91 for Indonesia, 0.99 for India) indicate the strong power of the three independent variables (i.e. competitive attitude, willingness to serve and speed) that together explain performance almost completely. Althougth 100\% explanatory power is, of course, unrealistic (Baumann et al., 2011), theoretically, the results indicate that the factors that most determine performance of 
the middle and working classes in emerging markets are competitive attitude, willingness to serve, and speed. It may be that working and middle class Indonesians and Indians have no other option than to focus on income generation and 'survival', and therefore have to be competitive, willing to serve and fast. Thus, the high explanatory power may well reflect reality in principle.

Empirically, such high values call for a comparison with results from other research. Economists have identified the 'Zipf law' (Gan et al., 2006), which states that while good fit is a statistical phenomenon often found in natural and social sciences, economists find it ‘spooky’ (Krugman, 1996). However and perhaps surprisingly, high explanatory power is not uncommon. For example, Rosen and Resnick (1980) found $\mathrm{R}^{2}$ values beyond 0.95 in 36 out of 44 countries in their research on the size distribution of cities. Values of 0.99 were found in an American study (Mills and Hamilton, 1994) and in a French study (Guerin-Pace, 1995), and values of 0.92 occurred in a study conducted in China (Song and Honglin Zhang, 2002). Thus, while admittedly high, the $\mathrm{R}^{2}$ values in this study are in line with many other social science studies.

\section{Asian countries in the Confucian orbit}

The second cluster of countries evident from the $\mathrm{R}^{2}$ analysis and independent sample t-tests (Table 2) are Asian countries in the Confucian orbit namely; China, Japan and Korea. The term 'Confucian orbit' is adopted because the cultures of these countries are all heavily influenced by Confucian values, albeit in different ways. These countries were categorised within the Confucian orbit based on their similarities as well as their differences. One similarity is the differing mean values for 'performance' for the middle vis-à-vis the working class. In the Asian Confucian orbit countries, the middle and working class start to experience diverging living conditions and attitudes, in contrast to the Asian emerging market countries. 
Another similarity is that the five predictors in combination strongly explain performance $\left(\mathrm{R}^{2}\right.$ of 0.809 for Japan, 0.84 for Korea and 0.932 for China).

With respect to the countries' differences, the explanatory variables of competitive attitude, willingness to serve and speed make different contributions to the $\mathrm{R}^{2}$ of performance for each of the countries. The contribution of the three variables to the $\mathrm{R}^{2}$ of performance is evenly distributed in the case of Korea (each roughly a third). In contrast, Chinese performance is heavily affected by speed (96\% of performance is explained by this variable). Speed also makes the greatest contribution to performance in Japan $\left(\mathrm{R}^{2}=69 \%\right)$, but this is lower than in China although higher than in Korea (35\%). For willingness to serve, Koreans' 'willingness to serve' makes the biggest contribution to performance (32.9\%, in contrast to 7\% in China and $18 \%$ in Japan). The role of 'competitive attitude' in Korea also makes the biggest contribution to performance among the Asian Confucian orbit countries (32\%, in contrast to $13 \%$ in Japan).

\section{Western countries with highly developed markets}

The third cluster, Western countries with highly developed markets consists of the USA, the UK and Germany. For these countries there is no significant difference between the middle class and working class performance means; both social classes experience relatively similar conditions and attitudes. In addition, the importance of the three variables; competitive attitude, willingness to serve and speed is significantly reduced for this cluster, explaining a mere $20-30 \%$ of performance ( $\mathrm{R}^{2}$ of 0.289 for the USA, 0.206 for the UK, and 0.202 for Germany). Identification of other factors that better explain performance for this cluster is beyond this study. 
Analysis of performance

The SEM analysis was followed by a UNINOVA of performance across the eight countries in order to test the country clusters emerging from the SEM results discussed previously. Table 3 shows the five clusters resulting from this analysis, supporting the overarching patterns that emerged from the SEM approach.

\section{Table 3 goes about here}

The three Western countries cluster together with performance levels of around 4 out of 7. Interestingly, Japan (4.1) is closer to (and in the same cluster as) the US as opposed to the UK, which only clusters with Germany and Japan. It clusters together with the US, the UK and Germany and is distinctively different from its neighbours, China and Korea (which cluster with neither Japan nor the West). Korea, on the other hand, has emerged as a unique case that has “cross-verged” (Ralston, 2008; Tung and Verbeke, 2010) with a performance level of 4.6. It is positioned half-way between the West and the emerging countries (e.g. China 5.0), reflecting Korea’s stage of industrialization. India and Indonesia are clustered together with the highest two performance levels, 5.2 and 5.4 respectively.

\section{Discussion}

The main purpose of this study was to investigate the mediating role of competitive attitude, willingness to serve and speed between individual workers' need for achievement and level of performance $\left(\mathrm{H}_{1 \mathrm{a}-\mathrm{c}}\right)$ and their need for power and level of performance $\left(\mathrm{H}_{2 \mathrm{a}-\mathrm{c}}\right)$. In addition, the final hypothesis was that performance is higher in Asian emerging and newly developed markets vis-à-vis Western developed markets. The findings of the study in relation to each hypotheses are shown in Table 4.

\section{Table 4 goes about here}


The first and second set of hypotheses on the mediating effects of competitive attitude, willingness to serve and speed are overwhelmingly supported. The hypotheses for developed Western markets are all supported except for Germany where competitive attitude was not found significant in mediating the relationship between need for achievement and performance. Newly developed markets such as Japan and Korea have identical patterns, i.e. all hypotheses are supported except the ones in relation to speed that was not found to significantly mediate the relationship between need for achievement and performance. Meanwhile emerging market countries such as China, Indonesia and India have a less clear pattern, with a different 4 (out of 6) hypotheses supported for each country (corresponding regression coefficients can be found in Appendix 2).

In relation to the final hypothesis, performance is higher in Asian emerging and newly developed markets than in Western developed markets in almost all cases. The only exception being that the performance for the USA is higher than for Japan.

Whilst the hypotheses were overwhelming supported, the extent to which competitive attitude, willingness to serve and speed explain performance varies across the eight countries, leading to the identification of three clear clusters of countries: Asian countries with emerging markets (India and Indonesia) where the three variables have considerable explanatory power; Asian countries in the Confucian orbit (China, Korea and Japan) where the three variables have considerable, albeit lower, explanatory power and the explanatory power of each variable differs greatly; and finally Western countries with highly developed markets (UK, USA and Germany) where the three variables have much less explanatory power altogether. Importantly, the three drivers explain performance powerfully for the Asian workforces but make a much weaker contribution to performance in the West. 
Actual performance levels (Table 2) are highest in the Asian emerging markets (e.g. Indonesian middle class $=5.4506$ and working class $=5.4024$; Table 2 ), generally followed by Asian Confucian orbit countries (e.g. Chinese middle class $=5.3460$ and working class $=$ 4.8438), and the lowest levels of performance are found in highly developed Western countries (e.g. German middle class $=4.0568$ and working class $=4.0312$ ). These findings are in reverse order to the GCI ranking from the World Economic Forum based on macro data, where the USA ( $\left.5^{\text {th }}\right)$, Germany $\left(6^{\text {th }}\right)$, Japan $\left(9^{\text {th }}\right)$ and the UK $\left(10^{\text {th }}\right)$ are among the top ten, Korea $\left(24^{\text {th }}\right)$ and China $\left(26^{\text {th }}\right)$ are lower down, and Indonesia $\left(46^{\text {th }}\right)$ and India $\left(56^{\text {th }}\right)$ rank lowest.

The different performance levels for the working and middle classes in the Confucian orbit countries perhaps indicate different living standards. In contrast, there are no differences in performance levels for the working and middle classes in emerging markets (i.e. working and middle classes in Indonesia and India face equal everyday life struggles) or in the developed West (i.e. working and middle classes in Germany, for example, may have equally comfortable everyday life circumstances).

The Asian emerging market countries (Indonesia and India) have similar patterns in terms of explanatory power and are ranked first and second for performance. For both countries, competitive attitude (26-30\%) and speed (63-66\%) in combination explain most of performance, indicating that their workforces may be well suited to IT, engineering, and research.

In relation to the Confucian orbit countries, Korea has the most balanced pattern in explaining performance of all the countries under investigation. This balance of the three factors in the Korean workforce suggests the Korean workforce is adaptable to different work styles; for example, service industries such as hospitality, or for fast-moving consumer goods markets 
such as consumer electronics. China, in contrast to the other Confucian orbit countries (Korea and Japan) as well as all the other countries in the study, is driven almost entirely by speed (96\%). This is relevant for industries that are driven by speed including electronics, fashion, and logistics. Speed also has high explanatory power in Japan, but not nearly to the same extent as in China, and in terms of actual performance level it is closer to the Western countries than it is to Korea and China. Arguably high income and wealth levels and a Western-style social welfare system have contributed to reduced performance levels in Japan in line with Western standards. In sum, whilst the model does have high explanatory power in Confucian orbit countries, each of the three factors has a different impact on performance depending on the country.

The Western countries studied were characterised by a low explanatory power of the tested predictors in explaining performance. This suggests that there are factors beyond this study's design that may best explain performance for the Western workforce. The levels of performance for these countries suggest that the working and middle classes in these countries have lower performance when contrasted with those in the Asian countries studied. This finding is not captured by the 'macro' measures of national competitiveness that are commonly used by the World Bank or the World Economic Forum, which generally rate the Western countries highly, and Asian countries less highly.

\section{Conclusion}

This study proposes and tests a model to explain performance at the individual worker's level combining McClelland's needs for achievement and power with three characteristics anticipated to be prevalent in Asian cultures: competitive attitude, willingness to serve, and speed. The study compared the significant predictors of performance across eight countries, revealing three distinct clusters; (1) Asian countries with emerging markets (Indonesia and India) where competitive attitude, willingness to serve and speed fully explain performance; 
(2) Asian countries in the Confucian orbit (China, Japan and Korea) where the predictors together explain 90\% of performance; and (3) Western countries with highly developed markets (USA, the UK and Germany) where the predictors explain only 20\%-30\% of performance. The three clusters are also supported by the workforce performance levels, in that the Asian emerging markets have the highest levels, followed by the Asian markets in the Confucian orbit and then the Western highly developed markets.

\section{Theoretical implications}

The study demonstrates that micro level factors, such as the ones used in this study, have a role to play in the modelling of performance, in that the results better accord with the greater economic growth and development experienced in Asian markets in recent years than rankings based macro level data (World Bank, United Nations, World Economic Forum).

The study contributes to Heskett and Schlesinger’s (1994) theory of the 'service profit chain’ by demonstrating how the crucial elements that drive workforce performance vary in different parts of the world. By combining motivational drivers identified by McClelland (1967) in a Western context with the mediating effects of motivational drivers more typical in an Asian context, the study provides a framework for modelling workforce performance in Asian markets, and potentially, using more appropriate mediating variables, in Western markets.

In relation to convergence, divergence or cross-vergence of cultures (Ralston et al. 2008) and regionalization (Rugman and Verbeke, 2004), the study supports a combination of the theories, in that the emerging Asian markets (India and Indonesia) and the highly developed Western markets (Germany, UK, USA) demonstrate convergence, whilst Japan diverged to the Western pattern of performance and Korea cross-verged and developed its own 'unique' workforce. The study found evidence of Confucian Heritage Cultures (Lee, 1996; Monkhouse 
et al., 2013; Yao et al., 2015) with China, Japan and Korea distinct from the non-Confucian Asian countries in the study (India and Indonesia). As such a new term: Confucian Orbit is introduced for Korea, China and Japan, countries where performance has dramatically improved and reached, if not superseded, the West. For example, fin hospitality; EastAsia has established new hotel brands that offer luxury and high standards at more affordable levels than in the West and receives superior consumer ratings, for example, andEast Asian airlines regularly win Skytrax awards for their service.

\section{Practical Implications}

Given the robustness of the results and their accordance with performance levels recently experienced by Asian markets, the study suggests that consideration should be given to incorporating the (type of) factors used in the study, along with the macro data currently used, in global indexes. By doing this, such indexes might more accurately reflect the performance of countries and address their apparent "skewing” in favour of Western countries.

The study establishes that the hypothesised drivers of performance: competitive attitude, willingness to serve and speed, explain performance extremely well in Asian countries. For hospitality and other service sectors, where the competitive edge is provided by the workers and their service delivery, this has implications for staff selection, training and management. The three drivers identified are crucial to create, generate and maintain performance and questions related to them can be used for staff selection and monitoring. If the three motivational drivers are maximised, a high level of performance should follow and so managing the drivers is likely to contribute to maintaining a constant quality of service delivery at the front line. More broadly, understanding which factors are most strongly associated with performance in different countries can inform decisions about which industry sectors to invest in, the location of business and outsourcing. 


\section{Limitations and future research}

This study deliberately incorporated factors that are more likely prevalent in Asian countries as mediators to link motivation to performance - a classic construct in human resource management(HRM) and motivational research in general. The model has relatively low explanatory power in Western countries and future research is required to investigate factors which are more likely to explain performance in Western countries. In addition, future research is required to investigate factors likely to moderate (this study looked at mediating effects only) the relationship between motivational needs and performance. For example, moderating effects could be expected from culture (e.g. power distance and long term orientation) and industrial development as captured by the United Nations Competitive Industrial Performance Index (UNIDO).

Ultimately, Baumann and Hamin (2011) establish that culture drives competitiveness and performance, and this study offers a better understanding how motivational and other factors that vary across cultures drive performance. Future research should probe motivation theory further on how the findings relate to Western and Asian (and other) cultures micro and macro level competitiveness and performance. 


\section{References}

Ashamalla, M. H. (1998), "International human resource management practices: the challenge of expatriation”, Competitiveness Review: An International Business Journal incorporating Journal of Global Competitiveness, Vol. 8 No. 2, pp. 54 - 65.

Banks, J. A. (1993), “Chapter 1: Multicultural education: historical development, dimensions, and practice”, Review of Research in Education, Vol. 19 No. 1, pp. 3-49.

Baumann, C., Elliott, G. and Hamin, H. (2011), “Modelling customer loyalty in financial services: a hybrid of formative and reflective constructs", International Journal of Bank Marketing, Vol. 29 No. 3, pp. 247-267.

Baumann, C. and Hamin, H. (2011), “The role of culture, competitiveness and economic performance in explaining academic performance: A Global Market Analysis for International Student Segmentation”, Journal of Marketing for Higher Education, Vol. 21 No. 2, pp. 181201.

Baumann, C. and Winzar, H. (2014), "The role of secondary education in explaining competitiveness”, Asia Pacific Journal of Education, (ahead-of-print), 1-18.

Baumann, C.,Hamin, H., and Seung Jung (SJ) Yang (2016), “Work ethic formed by pedagogical approach: an evolution of institutional approach to education and competitiveness in Asia vis-à-vis the West”, Asia Pacific Business Review, (forthcoming).

Bollen, K. A. (1989), Structural equations with latent variables, New York.

Boltho, A. (1996), “The assessment: international competitiveness”, Oxford Review of Economic Policy, Vol. 12 No. 3, pp. 1-16.

Bourdieu, P. (1997), “The forms of capital”, Halsey, A., Lauder, H., Brown, P. and Stuartwells, A. (Eds.), Education: Culture, economy and society. Oxford: Oxford University Press.

Brislin, R. W. and Kim, E. S. (2003), "Cultural diversity in people's understanding and uses of time”, Applied Psychology, Vol. 52 No. 3, pp. 363-382.

Burckle, M. A., Ryckman, R. M., Gold, J. A., Thornton, B. and Audesse, R. J. (1999), “Forms of Competitive Attitude and Achievement Orientation in Relation to Disordered Eating”, Sex Roles, Vol. 40 No. 11, pp. 853-870.

Byrne, B. (2006), Structural Equation Modeling with Eqs: basic concepts, applications, and programming (Multivariate Applications) (Multivariate Applications Series).

Chang, C.-C. and Luh, Y.-H. (1999), "Efficiency change and growth in productivity: the Asian growth experience”, Journal of Asian Economics, Vol. 10 No. 4, pp. 551-570.

Chang, S. J., van Witteloostuijn, A., and Eden, L. (2010), “From the editors: common method variance in international business research", Journal of International Business Studies, Vol. 41 No. 2, pp. 178-184.

Chen, M. (2004), Asian Management Systems, London, Thomson. 
Cole, M. and Bruner, J. S. (1971), “Cultural differences and inferences about psychological processes”, American Psychologist, Vol. 26 No. 10, pp. 867-876.

Covington, M. V. (2000), "Goal theory, motivation, and school achievement: an integrative review”, Annual review of psychology, Vol. 51: 171-200.

Craighead, C. W., Ketchen, D. J., Dunn, K. S., and Hult, G. G. (2011), “Addressing common method variance: guidelines for survey research on information technology, operations, and supply chain management”, IEEE Transactions on Engineering Management, Vol. 58 No. 3, pp. 578-588.

Dickinson, L. (1995), “Autonomy and motivation a literature review”, System, Vol. 23 No. 2, pp. 165-174.

Fairhurst, D. (2008), “Am I 'bovvered'? Driving a performance culture through to the front line”, Human Resource Management Journal, Vol. 18 No. 4), 321-326. doi:10.1111/j.17488583.2008.00080.x

Frischer, J. (1993), “Empowering management in new product development units”, Journal of Product Innovation Management, Vol. 10 No. 5, pp. 393-401.

Fukurai, H. and Krooth, R. (2010), "What brings people to the courtroom? Comparative analysis of people’s willingness to serve as jurors in Japan and the U.S.”, International Journal of Law, Crime and Justice, Vol. 38 No. 4, pp. 198-215.

Gan, L., Li, D. and Song, S. (2006), "Is the Zipf law spurious in explaining city-size distributions?”' Economics Letters, Vol. 92 No. 2, pp. 256-262.

Garhammer, M. (2002), "Pace of life and enjoyment of life”, Journal of Happiness Studies, Vol. 3 No. 3, pp. 217-256.

Guerin-Pace, F. (1995), "Rank-size distribution and the process of urban growth”, Urban Studies, Vol. 32 No. 3, pp. 551-562.

Harris, I. C. and Shimizu, K. (2004), “Too busy to serve? An examination of the influence of overboarded directors”, Journal of Management Studies, Vol. 41 No. 5, pp. 775-798.

Heskett, J. L., and Schlesinger, L. A. (1994), "Putting the service-profit chain to work”, Harvard business review, Vol. 72 No. 2), 164-174.

Hickman, B. G. (1992), International productivity and competitiveness, New York, NY: Oxford University Press.

Huggins, R. and Thompson, P. (2011), "Well-being and competitiveness: are the two linked at a place-based level?”, Cambridge Journal of Regions, Economy and Society.

Hwang, A. and Arbaugh, J. B. (2006), "Virtual and traditional feedback-seeking behaviors: underlying competitive attitudes and consequent grade performance", Decision Sciences Journal of Innovative Education, Vol. 4 No. 1, pp. 1-28. 
King, R. B., Mcinerney, D. M. and Watkins, D. A. (2012), “Competitiveness is not that bad....at least in the East: testing the hierarchical model of achievement motivation in the Asian setting”, International Journal of Intercultural Relations, (0).

Krugman, K. (1996), The Self-Organizing Economy, Malden, MA: Blackwell Publishing Inc.

Lai, J., S. Lui, S., and H.Y. Hon, A. (2014), “Does standardized service fit all?”, International Journal of Contemporary Hospitality Management, Vol. 26 No. 8), 1341-1363.

doi:10.1108/ijchm-08-2013-0338

Lee, W. O. (1996), "The cultural context for Chinese learners: conceptions of learning in the Confucian tradition”, Watkins, D.A. and Biggs, J.B. (Eds.), The Chinese learner: Cultural, psychological and contextual influences, Hong Kong: Comparative Education Research Centre and The Australian Council for Educational Research.

Lee, M. J., and Back, K. J. (2005), “A review of economic value drivers in convention and meeting management research”, International Journal of Contemporary Hospitality Management, Vol. 17 No. 5), 409-420.

Levine, R. V. and Bartlett, K. (1984), "Pace of life, punctuality, and coronary heart disease in six countries”, Journal of Cross-Cultural Psychology, Vol. 15 No. 2, pp. 233-255.

Levine, R. V. and Norenzayan, A. (1999), “The pace of life in 31 countries”, Journal of Cross-Cultural Psychology, Vol. 30 No. 2, pp. 178-205.

Ling, O. G., Ser, T. E. and Koh, G. (1999), "Political participation in Singapore: findings from a national survey”, Asian Journal of Political Science, Vol. 7 No. 2, pp. 126-141.

Lynn, G. S., Abel, K. D., Valentine, W. S. and Wright, R. C. (1999a), "Key factors in increasing speed to market and improving new product success rates", Industrial Marketing Management, 28 No. 4, pp. 319-326.

Lynn, G. S., Skov, R. B. and Abel, K. D. (1999b), "Practices that support team learning and their impact on speed to market and new product success", Journal of Product Innovation Management, Vol. 16 No. 5, pp. 439-454.

Martin, K. E. (2000), "Nurse practitioners: a comparison of rural-urban practice patterns and willingness to serve in underserved Areas", Journal of the American Academy of Nurse Practitioners, Vol. 12 No. 12, pp. 491-496.

McClelland, D. C. (1967), Achieving Society, Free Pr.

Mcneese-Smith, D. K. (1999), “The relationship between managerial motivation, leadership, nurse outcomes and patient satisfaction”, Journal of Organizational Behavior, Vol. 20 No. 2, pp. 243-259.

Mills, E. S. and Hamilton, B. W. (1994), Urban Economics, New York, Harper Collins College Publishers.

Monkhouse, L. L., Barnes, B. R., and Hanh Pham, T. S. (2013), "Measuring Confucian values among East Asian consumers: a four country study”, Asia Pacific Business Review, Vol. 19 No. 3), 320-336. 
Nowell, A. (2010), "Working memory and the speed of life”, Current Anthropology, Vol. 51 No. S1, pp. S121-S133.

Oral, M., Cinar, U. and Chabchoub, H. (1999), "Linking industrial competitiveness and productivity at the firm level”, European Journal of Operational Research, Vol. 118 No. 2, pp. 271-277.

Podsakoff, P. M., MacKenzie, S. B., Lee, J. Y., and Podsakoff, N. P. (2003), “Common method biases in behavioral research: A critical review of the literature and recommended remedies”, Journal of applied psychology, Vol. 88 No. 5, pp. 879-903.

Porter, M. E. (1980), Competitive Strategy, New York, The Free Press.

Ralston, D. A. (2008), “The crossvergence perspective: reflections and projections”, Journal of International Business Studies, Vol. 39: 27-40.

Ramlall, S., (2004), “A review of employee motivation theories and their implications for employee retention within organizations”, Journal of American Academy of Business, Vol. 5 No. 1/2, pp. 52-63.

Rose, M. R., Diamond, S. S. and Musick, M. A. (2012), "Selected to serve: an analysis of lifetime jury participation”, Journal of Empirical Legal Studies, Vol. 9 No. 1, pp. 33-55.

Rosen, K. T. and Resnick, M. (1980), “The size distribution of cities: an examination of the Pareto law and primacy”, Journal of Urban Economics, Vol. 8 No. 2, pp. 165-186.

Rugman, A. M., and Verbeke, A. (2004), “A perspective on regional and global strategies of multinational enterprises”, Journal of International Business Studies, Vol. 35 No. 1, pp. 3-18.

Ryckman, R. M., Hammer, M., Kaczor, L. M. and Gold, J. A. (1996), “Construction of a personal development competitive attitude scale”, Journal of Personality Assessment, Vol. 66 No. 2, pp. 374-385.

Sarros, J. C., Gmelch, W. H. and Tanewski, G. A. (1997), “The role of department head in Australian universities: tasks and stresses”, Higher Education Research and Development, Vol. 16 No. 3, pp. 283-292.

Schwab, K. and Sala-I-Martin, X. (2011), The Global Competitiveness Report 2011-2012, World Economic Forum.

Serneels, P., Lindelow, M., Montalvo, J. G. and Barr, A. (2007), "For public service or money: understanding geographical imbalances in the health workforce”, Health Policy and Planning, Vol. 22 No. 3, pp. 128-138.

Shadur, M. A., Rodwell, J. J. and Bamber, G. J. (1995), "Factors predicting employees' approval of lean production”, Human Relations, Vol. 48 No. 12, pp. 1403-1425.

Singh, R., Poh, W. Y. and Chang, A. P. M. (2008), "Competitive versus cooperative attitudes in crossed categorization effects: Testing the Category Dominance and Equivalence Models", The Journal of Social Psychology, Vol. 148 No. 1, pp. 5-20. 
Smith, C. S., Ester, T. V. and Inglehart, M. R. (2006), "Dental education and care for underserved patients: an analysis of students' intentions and alumni behavior”, Journal of Dental Education, Vol. 70 No. 4, pp. 398-408.

Smith, E. (2008), Using Secondary Data in Educational and Social Research. England, Open University Press.

Song, S. and Honglin Zhang, K. (2002), "Urbanisation and city size distribution in China”, Urban Studies, Vol. 39 No. 12, pp. 2317-2327.

Tu, H. T. and Ginsburg, P. B. (2006), “Losing ground: physician income, 1995-2003”, Tracking Report, 15.

Tung, R. and Verbeke, A. (2010), "Beyond Hofstede and GLOBE: improving the quality of cross-cultural research”, Journal of International Business Studies, Vol. 41 No. 8, pp. 12591274.

UNIDO. (2013), Competitive Industrial Performance Report 2012-2013. Vienna; Austria.

Vesey, J. T. (1991), “The new competitors: they think in terms of 'speed-to-market”, The Executive, Vol. 5 No. 2, pp. 23-33.

Vigoda, E. (2000), “Are you being served? The responsiveness of public administration to citizens' demands: an empirical examination in Israel”, Public Administration, Vol. 78 No. 1, pp. 165-191.

Wagner, J. (2007), "Exports and productivity: a survey of the evidence from firm-level data”, World Economy, Vol. 30 No. 1, pp. 60-82.

Woods, J., Winakor, G., Maldonado, E., Alaghehband, A. and Adams, S. (1981), "Relationship between measures of thermal environment and measures of worker productivity”, ASHRAE Transactions, 117-144.

Yao, W., Baumann, C., and Tan, L. (2015), "Wine brand category choice and Confucianism: a purchase motivation comparison of Caucasian, Chinese and Korean consumers”, MartínezLópez,F.J., Gázquez-Abad, J.C. and Sethuraman, R. (Eds.), Advances in National Brand and Private Label Marketing (pp. 19-33). Cham; Switzerland: Springer International Publishing. doi:10.1007/978-3-319-20182-5_3

Yu, A. B. and Yang, K. S. (1994), "The nature of achievement motivation in collectivist societies”, Kim, U.E., Triandis, H.C.E, Kâğitçibaşi, Ç. E., Choi, S.C.E. and Yoon, G.E. (Eds), Individualism and collectivism: Theory, method, and applications. 


\section{Appendix 1}

Key questionnaire items (all measured on a 7 point Likert scale)

\section{Need for achievement}

I want to know how I am progressing as I complete tasks.

I enjoy setting and achieving realistic goals.

I enjoy the satisfaction of completing a difficult task.

\section{Need for power}

I enjoy leading and being in charge.

I enjoy influencing other people to get my way.

In a leaderless situation I tend to take charge.

\section{Competitive attitude}

I enjoy competition because it tends to bring out the best in me rather than as a means of feeling better than others.

I like competition because it teaches me a lot about myself.

I find competition enjoyable because it lets me express my own potentials and abilities during competition.

I enjoy competition because it brings me to a higher level of motivation to bring the best out of myself rather than as a means of doing better than others.

\section{Willingness to serve}

I am willing to 'serve' someone such as a customer/superior in order to do a good job.

\section{Speed}

I make quick decisions.

I do everything fast.

\section{Performance}

Right now I am working harder than usual.

The amount of work I have already done this year is more than usual.

I am productive. 


\section{Appendix 2}

\section{Regression Coefficients}

\begin{tabular}{|c|c|c|c|c|c|c|c|c|c|c|}
\hline & & & Indonesia & India & China & Japan & Korea & USA & UK & Germany \\
\hline NEED FOR ACHIEVEMENT & $\rightarrow$ & COMPETITIVE ATTITUDE & $0.6^{+)}$ & 0.393 & $0.006^{+}$ & 0.301 & 0.247 & 0.358 & 0.281 & $0.067^{+}$ \\
\hline NEED FOR ACHIEVEMENT & $\rightarrow$ & WILLINGNESS TO SERVE & $0.553^{+)}$ & 0.515 & 0.196 & 0.298 & 0.445 & 0.629 & 0.367 & 0.253 \\
\hline NEED FOR ACHIEVEMENT & $\rightarrow$ & SPEED & 0.176 & $0.1^{+)}$ & 0.687 & 0.176 & $\mathbf{0 . 1 0 9}^{+)}$ & $\mathbf{0 . 0 0 9}^{+}$ & 0.131 & 0.306 \\
\hline NEED FOR POWER & $\rightarrow$ & COMPETITIVE ATTITUDE & 0.326 & 0.538 & 0.907 & 0.587 & 0.556 & 0.433 & 0.497 & 0.583 \\
\hline NEED FOR POWER & $\rightarrow$ & WILLINGNESS TO SERVE & 0.093 & $0.123^{+)}$ & 0.829 & 0.43 & 0.278 & 0.203 & 0.127 & 0.245 \\
\hline NEED FOR POWER & $\rightarrow$ & SPEED & 0.619 & 0.787 & -0.141 & 0.604 & 0.616 & 0.712 & 0.684 & 0.625 \\
\hline COMPETITIVE ATTITUDE & $\rightarrow$ & PERORMANCE & 0.298 & 0.337 & $-0.028^{+)}$ & 0.16 & 0.363 & 0.215 & 0.188 & 0.246 \\
\hline WILLINGNESS TO SERVE & $\rightarrow$ & PERORMANCE & 0.162 & $0.066^{+)}$ & 0.103 & 0.238 & 0.385 & 0.166 & 0.105 & 0.157 \\
\hline SPEED & $\rightarrow$ & PERORMANCE & 0.634 & 0.683 & 0.93 & 0.653 & 0.398 & 0.292 & 0.289 & 0.193 \\
\hline
\end{tabular}

+) $p$-value $>0.05$ 
Figure 1. Model

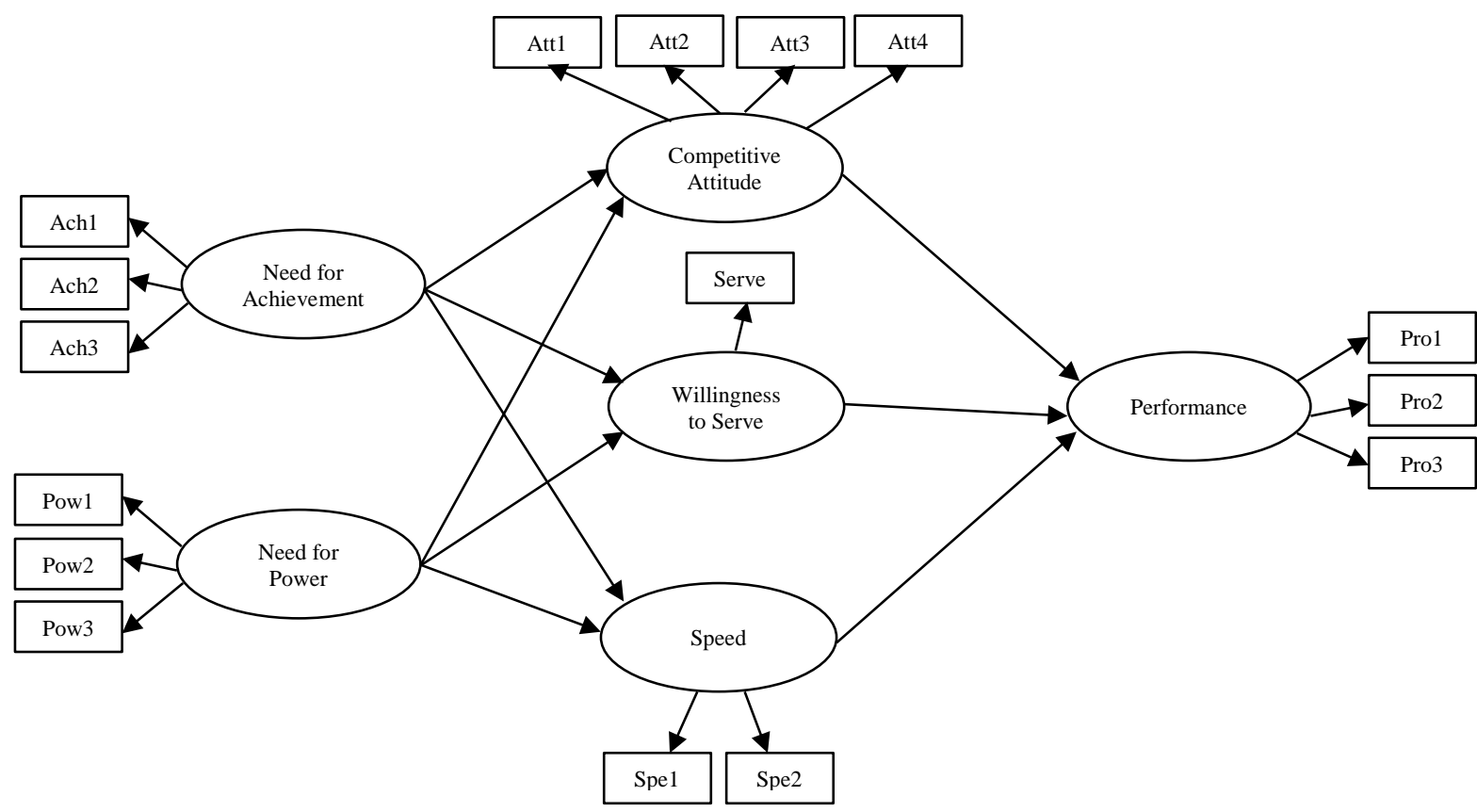


Table 1. ULMC Korea

\begin{tabular}{|l|l|l|l|l|l|l|}
\hline Model & Chi-square & DF & p-value & NFI & RFI & TLI \\
\hline $\begin{array}{l}\text { Baseline (without } \\
\text { common latent } \\
\text { factor) }\end{array}$ & 248.935 & 68 & 0.000 & 0.934 & 0.898 & 0.898 \\
\hline $\begin{array}{l}\text { Unmeasured latent } \\
\text { Factor }\end{array}$ & 246.565 & 83 & 0.000 & 0.935 & 0.918 & 0.944 \\
\hline Difference & -2.370 & 15 & 1.00 & -0.001 & -0.019 & -0.020 \\
\hline
\end{tabular}


Table 2. $R^{2}$, contribution to $R^{2}$ and independent sample $t$-test

\begin{tabular}{|c|c|c|c|c|c|c|c|}
\hline \multirow{2}{*}{ Country } & \multicolumn{3}{|c|}{$\begin{array}{l}\text { Contribution to } \mathbf{R}^{2} \text { Performance } \\
(\%)\end{array}$} & \multirow{2}{*}{$\begin{array}{l}\mathbf{R}^{2} \\
\text { Performanc } \\
\text { e }\end{array}$} & \multicolumn{3}{|c|}{ T-test of performance mean } \\
\hline & $\begin{array}{l}\text { Competitive } \\
\text { attitude }\end{array}$ & $\begin{array}{l}\text { Willingnes } \\
\text { s to serve }\end{array}$ & Speed & & $\begin{array}{l}\text { Middle } \\
\text { class }\end{array}$ & $\begin{array}{l}\text { Working } \\
\text { class }\end{array}$ & \\
\hline \multirow{4}{*}{$\begin{array}{l}\text { Indonesi } \\
\text { a }\end{array}$} & \multirow{3}{*}{$26.30 \%$} & \multirow{3}{*}{$10.86 \%$} & \multirow{3}{*}{$62.84 \%$} & \multirow{3}{*}{0.91} & 377 & 128 & $\mathrm{~N}$ \\
\hline & & & & & 5.4506 & 5.4024 & Mean \\
\hline & & & & & \multicolumn{2}{|l|}{0.608} & $p$-value \\
\hline & \multirow{3}{*}{$29.89 \%$} & \multirow{3}{*}{$3.79 \%$} & \multirow{3}{*}{$66.25 \%$} & \multirow{3}{*}{0.999} & 389 & 59 & $\mathrm{~N}$ \\
\hline \multirow[t]{2}{*}{ India } & & & & & 5.1842 & 5.4469 & Mean \\
\hline & & & & & \multicolumn{2}{|l|}{0.112} & $p$-value \\
\hline \multirow{3}{*}{ China } & \multirow{3}{*}{$-2.52 \%$} & \multirow{3}{*}{$6.65 \%$} & \multirow{3}{*}{$95.99 \%$} & \multirow{3}{*}{0.932} & 175 & 351 & $\mathrm{~N}$ \\
\hline & & & & & 5.3460 & 4.8438 & Mean \\
\hline & & & & & \multicolumn{2}{|l|}{$<0.001$} & $p$-value \\
\hline \multirow{4}{*}{$\begin{array}{l}\text { South } \\
\text { Korea }\end{array}$} & \multirow{3}{*}{$32.07 \%$} & \multirow{3}{*}{$32.86 \%$} & \multirow{3}{*}{$35.01 \%$} & \multirow{3}{*}{0.84} & 275 & 230 & $\mathrm{~N}$ \\
\hline & & & & & 4.7248 & 4.4958 & Mean \\
\hline & & & & & 0.013 & & $p$-value \\
\hline & \multirow{3}{*}{$12.95 \%$} & \multirow{3}{*}{$18.24 \%$} & \multirow{3}{*}{$68.85 \%$} & \multirow{3}{*}{0.809} & 267 & 299 & $\mathrm{~N}$ \\
\hline \multirow[t]{2}{*}{ Japan } & & & & & 4.1543 & 3.9821 & Mean \\
\hline & & & & & 0.035 & & $p$-value \\
\hline & & & & & 300 & 214 & $\mathrm{~N}$ \\
\hline USA & $31.92 \%$ & $22.23 \%$ & $45.87 \%$ & 0.289 & 4.3373 & 4.2333 & Mean \\
\hline & & & & & 0.435 & & $p$-value \\
\hline & & & & & 239 & 288 & $\mathrm{~N}$ \\
\hline UK & $32.12 \%$ & $11.26 \%$ & $56.54 \%$ & 0.206 & 3.8974 & 4.0352 & Mean \\
\hline & & & & & 0.251 & & $p$-value \\
\hline & & & & & 369 & 151 & $\mathrm{~N}$ \\
\hline Germany & $44.82 \%$ & $20.99 \%$ & $33.82 \%$ & 0.202 & 4.0568 & 4.0312 & Mean \\
\hline & & & & & 0.841 & & $p$-value \\
\hline
\end{tabular}


Table 3. Univariate analysis of variance of performance

\begin{tabular}{|ll|l|l|l|l|l|l|}
\hline & & \multicolumn{5}{|l|}{ Subset } & \\
\cline { 4 - 7 } & Country & $\mathrm{N}$ & 1 & 2 & 3 & 4 & 5 \\
\hline Scheffe test & UK & 527 & 3.9727 & & & & \\
& Germany & 520 & 4.0493 & 4.0493 & & & \\
& Japan & 566 & 4.0634 & 4.0634 & & & \\
USA & 514 & & 4.2940 & & & \\
& South Korea & 505 & & & 4.6205 & & \\
China & 526 & & & & 5.0109 & \\
& India & 448 & & & & 5.2188 & 5.2188 \\
& Indonesia & 505 & & & & & 5.4384 \\
Sig. & & .982 & .144 & 1.000 & .345 & .269 \\
\hline
\end{tabular}




\section{Table 4. Hypotheses and conclusions}

\begin{tabular}{|c|c|c|c|c|c|c|c|c|}
\hline & Indonesia & India & China & Japan & Korea & USA & UK & Germany \\
\hline \multicolumn{9}{|c|}{ Relationship and mediation (based on regression coefficients) } \\
\hline $\begin{array}{l}\mathrm{H}_{1 \mathrm{a}} \text { : Competitive attitude significantly } \\
\text { mediates the relationship between need } \\
\text { for achievement and performance. }\end{array}$ & $\begin{array}{c}\text { Not } \\
\text { supported }\end{array}$ & Supported & $\begin{array}{c}\text { Not } \\
\text { supported }\end{array}$ & Supported & Supported & Supported & Supported & $\begin{array}{c}\text { Not } \\
\text { supported }\end{array}$ \\
\hline $\begin{array}{l}\mathrm{H}_{1 \mathrm{~b}} \text { : Willingness to serve significantly } \\
\text { mediates the relationship between need } \\
\text { for achievement and performance. }\end{array}$ & $\begin{array}{c}\text { Not } \\
\text { supported }\end{array}$ & Supported & Supported & Supported & Supported & Supported & Supported & Supported \\
\hline $\begin{array}{l}\mathrm{H}_{1 \mathrm{c}} \text { : Speed of life significantly } \\
\text { mediates the relationship between need } \\
\text { for achievement and performance. }\end{array}$ & Supported & $\begin{array}{c}\text { Not } \\
\text { supported }\end{array}$ & Supported & $\begin{array}{c}\text { Not } \\
\text { supported }\end{array}$ & $\begin{array}{c}\text { Not } \\
\text { supported }\end{array}$ & Supported & Supported & Supported \\
\hline $\begin{array}{l}\mathrm{H}_{2 \mathrm{a}} \text { : Competitive attitude significantly } \\
\text { mediates the relationship between need } \\
\text { for power and performance. }\end{array}$ & Supported & Supported & $\begin{array}{c}\text { Not } \\
\text { supported }\end{array}$ & Supported & Supported & Supported & Supported & Supported \\
\hline $\begin{array}{l}\mathrm{H}_{2 b} \text { : Willingness to serve significantly } \\
\text { mediates the relationship between need } \\
\text { for power and performance. }\end{array}$ & Supported & $\begin{array}{c}\text { Not } \\
\text { supported }\end{array}$ & Supported & Supported & Supported & Supported & Supported & Supported \\
\hline $\begin{array}{l}\mathrm{H}_{2 c} \text { : Speed of life significantly } \\
\text { mediates the relationship between need } \\
\text { for power and performance. }\end{array}$ & Supported & Supported & Supported & Supported & Supported & Supported & Supported & Supported \\
\hline \multicolumn{9}{|l|}{ Performance difference } \\
\hline $\begin{array}{l}\mathrm{H}_{3} \text { :Performance is higher in Asian } \\
\text { emerging and newly developed markets } \\
\text { vis-à-vis Western developed markets. }\end{array}$ & \multicolumn{8}{|c|}{ Supported } \\
\hline
\end{tabular}

